\title{
Taking the Thai Trail: Attracting FDI via Macro-Level Policy.
}

\author{
Bhagaporn Wattanadumrong ${ }^{1,2}$, Alan Collins ${ }^{2}$, Martin C. Snell ${ }^{2}$ \\ ${ }^{1}$ Pibulsongkram Rajabhat University,Thailand \\ ${ }^{2}$ University of Portsmouth, UK
}

\section{Corresponding Author:}

Prof. Alan Collins

Economics and Finance Group

University of Portsmouth

Richmond Building, Portland Street,

Portsmouth, Hampshire PO1 3DE

UNITED KINGDOM

Tel: +44(0) 2392844128

Fax: +44(0) 2392844038

Email: alan.collins@port.ac.uk

\begin{abstract}
This study reports on the establishment of an extensive and detailed composite dataset to support country-level econometric studies of FDI in Thailand. This has permitted investigation in detail, for the first time, of the key macroeconomic determinants of FDI in Thailand over the period 1970-2004. In particular, the influence of interest rates, exchange rates, volumes of trade, wage rates and geographical distance on FDI were considered and the results are reviewed in the context of other country studies.
\end{abstract}

Keywords: Foreign Direct Investment, Thailand, Pooled Data, GMM 


\section{Introduction}

This study features the first major econometric analysis of the determinants of FDI in Thailand employing an approach that is strongly influenced by the work of Wei and Liu (2001). They examined the determinants of FDI in China with respect to a wide range of country characteristics and also extended the literature by employing a dynamic panel data approach in their econometric work. This paper complements that work with analysis of a detailed composite Thai FDI dataset, covering the time period 1970-2004, assembled from many different sources and subject to considerable integrity testing. The model estimates generated permit the first detailed investigation of how macroeconomic policy and other variables determine FDI in Thailand. The findings provide evidence from panel data estimation that volumes of trade, relative wage rates and geographical distance are significant determinants of FDI in a manner consistent with several other country studies. At the same time, it would seem that explaining differences in FDI to Thailand from the major investing countries by reference to Thai macro-level economic policy is difficult and that in many respects it is the economic conditions in these countries that could be more important than policies implemented in Thailand. Thailand's policies to attract FDI may be more efficiently concentrated on local incentives and institutional factors.

\section{FDI into Thailand - Policies and Trends}

Our focus for empirical investigation is to examine factors influencing FDI into Thailand over the years $1970-2004^{1}$. Government policy on FDI can be made through direct FDI initiatives (eg. tax incentives) as well as indirectly and maybe as a spin-off from broader macroeconomic policy (eg. interest rates). This distinction is important for two reasons. Firstly, it is possible that direct and indirect influences pull in opposite directions, especially as the Thai economy may have to give a higher priority to responding to the macroeconomic climate. Secondly, policy which concentrates on the macroeconomic instruments may be 
more (or less) effective in attracting FDI than direct FDI initiatives. This paper attempts to assess the effect of changes in the macroeconomic variables on FDI in the context of the overall economic policy in Thailand. Over the last 60 years, Thailand has been transformed from a relatively poor and predominantly agricultural economy to a fast-growing one with an emphasis on manufacturing. Between 1960 and 2011, 10 National Development Plans prepared under the auspices of the National Economic and Social Development Board (NESDB) have set out various economic and social objectives, most of which include some reference to economic growth, and attracting FDI has played a prominent role. The mechanisms for achieving economic growth have changed over time, initially with policies aimed at import substitution, later changing to export promotion, usually via trade tariff changes and incentive schemes for investment and relief from taxes on export sales. FDI was specifically encouraged from around 1985 through grants and the easing of restrictions on foreign equity ownership in firms producing goods for export. In the seventh (1992-1996) and eighth (1997-2001) plans, the government emphasised achieving economic growth with "human resources" as the central platform by developing skills, technology and basic infrastructure in order to serve the demands of foreign investors.

The institutional framework under which the NESDB looked to implement these plans consisted of three ministries responsible to the NESDB - the Ministry of Industry, the Ministry of Finance and the Ministry of Commerce. In terms of attracting FDI, the Ministry of Industry and its agencies administer and implement investment promotion law to encourage the establishment of new and existing industries via tax and non-tax incentives as well as a relocation policy which can be summarised as the decentralisation of industrial investment away from Bangkok into the remoter regions of Thailand. Clearly, over the 35 years of this study, many varied specific incentives to encourage investment, both at national and local level. Their impact on FDI is not considered in detail in this paper (see 
Wattanadumrong et al. (2010) for an analysis of FDI to regions). The macroeconomic policies which are under scrutiny here have been the responsibility of agencies in the Ministry of Finance, particularly the Bank of Thailand which exercises control over Thailand's monetary, fiscal and foreign exchange policy.

Figure 1 shows trends in real FDI inflows to Thailand since 1970. The solid black line shows the index number of total FDI $(2000=100)$ from the rest of world and the large increase since the late 1980's is clearly evident. More recent trends show remarkable resilience in spite of considerable macroeconomic instability arising from both domestic and world economic crises. From 1970 there was little movement in FDI but in the second half of the 1980s the Plaza Accord raised the costs of production, especially labour costs in many potential investing countries, which led to the relocation of production bases to Thailand and other developing countries (Pupphavesa and Pussarungsri (1994)) and to increases in the volume of FDI inflow. During the period 1991-1996, FDI peaked at around 200,000 million Thai Baht in 1992, which dropped between 1993 and 1994 to approximately 70,000 million Baht as the effects of the political instability in the early 1990s affected foreign investor confidence. During this period, FDI was concentrated in steel, petrochemical and construction projects. Nevertheless, it then grew rapidly to a peak in 1997 before the depreciation of the Thai Baht in July of that year. The substantial fall in the period 1997-1999 was reversed in 2000, slightly dropping back again from 2001 onwards. One aim of this paper is to elicit the extent to which changes in economic conditions in Thailand have led to changes in the total inflow to Thailand (the pull factors).

In contrast, but of equal interest in examining the determinants of FDI, this paper also looks at the source of the additional FDI and attempts to assess which factors lead to variations between investing countries. To the extent that there are varying economic conditions between investing countries, this may help elicit what are termed the push factors. 
Although data for total FDI inflows to Thailand are available, the breakdown into all individual countries was not available consistently, and this study concentrates on 10 major investing countries (Japan, USA, UK, Germany, Canada, Australia, Hong Kong, Singapore, Taiwan, and Korea) ${ }^{2}$. Figure 1 shows the trends in real FDI for these countries. The most notable point is the dramatic volatility of the FDI from each country after 1990 - no country seemed exempt. By its nature, FDI from any one investing company may be erratic and projects/equity purchases/loans etc. may be one-off and/or for very large amounts. However, one might have expected some smoothing from one year to the next once the micro data had been aggregated to provide the overall figures and since, apart from major crises, economic conditions and their forecasts change only slowly.

The dominant sources of FDI inflow have varied over time, with each of USA, Japan and Singapore vying for top place, the last asserting itself strongly over the final few years of the data set. To more clearly see behind the overall levels of FDI, Figure 2 shows the percentage of total real FDI from these 10 countries. This naturally supports the trends in Figure 1, but also shows the steady decline of the share in FDI from the USA (with some clear cycles) as well as the increasing prominence of Singapore, the reasonably consistent percentage from Japan (excluding the peak in the mid 1980's) and the rise and fall of the contribution from Hong Kong. The cyclical and erratic nature of the FDI from each country is evident. Although the totals of FDI for each country perhaps reveal an increasing exponential trend over the very long term, there is no steady annual trend in which one country slowly gains at the expense of another. Naturally, each investing country will be at somewhat different stages in the business cycle, and this may explain a small part of the variation due to the push factors (see Yeyati et al., 2007, for a multinational model looking at how these factors affect FDI). Further, all 10 countries face the same pull factors in Thailand. It is of course possible that countries (or more precisely the residents of countries) differ in the 
extent to which changes in Thai economic conditions (and expectations about these changes) influence their inclination to change levels of FDI, but this overview of trends suggests that there may be a considerable element in the variations in FDI that will be difficult to explain. Many random factors, perhaps unique and not known at the macro level of aggregation, may be involved. The model estimated below is the first attempt to explain variations in FDI to Thailand from individual countries, using both push and pull factors, taking variables drawn from the standard FDI literature.

Figure 1. Total Real FDI - Thailand 1970 - 2004

Figure 2. Relative Shares in Real FDI - Thailand 1970 - 2004

\section{Variables and model formulation.}

Many models have been developed and estimated to investigate and explain the general nature and motivations for $\mathrm{FDI}^{3}$. In considering investment alternatives, firms are likely to consider both home investment and foreign investment, each of which will have differing costs and estimated benefits to the firm and shareholders. The motivation for a potential investor may be based around expected long-term maximization of profits, where those possibilities offering the greatest return (either at home or abroad) will be taken up first. Thus variations in investment to Thailand at any point in time will depend on the likely relative, marginal and absolute values of variables in Thailand (and indeed in all other countries) compared to the investing country.

Capturing the expected relative returns from investment in these complementary home and foreign markets in an economic model has posed difficulties in econometric modeling, which have been approached in differing ways. To the extent that firms consider the whole world as a potential for investment, a general equilibrium approach to FDI might have some mileage. In this study, however, we follow the partial approach of considering 
FDI into just one country (Thailand) from each of 10 relatively large or neighbouring economies.

As noted above, FDI from the 10 countries selected displays somewhat erratic movements over time and our emphasis is focussed on modelling short-term dynamic effects rather than searching for some long-term equilibrium relationship between all variables. Following other studies (e.g. Merlevede and Schoors, 2009), a partial stock-adjustment model links attained levels or changes in FDI to Thailand from country $i$ at time $t\left(\mathrm{FDI}_{\mathrm{i}, \mathrm{t}}\right)$ to desired levels $\left(\mathrm{FDI}_{\mathrm{i}, \mathrm{t}}^{*}\right)$, with an adjustment parameter $\alpha$, reflecting the sluggishness with which FDI proposals can be implemented:

$$
F D I_{i, t}-F D I_{i, t-1}=\alpha\left(F D I^{*}{ }_{t}-F D I_{i, t-1}\right) \quad i=1,2, \ldots 10 ; t=1,2, \ldots T
$$

The desired level of FDI is related to a vector $x$ of the explanatory variables discussed above, as follows:

$$
F D I^{*}{ }_{i, t}=\beta^{\prime} x_{i, t}
$$

With the addition of appropriate error terms for a panel representation, this leads to a final model for estimation of

$$
F D I_{i, t}=(1-\alpha) F D I_{i, t-1}+\gamma^{\prime} x_{i, t}+u_{i, t} \quad \text { where } u_{i, t}=\delta_{i}+\varepsilon_{i, t}
$$

$\delta_{\mathrm{i}}$ is a term to allow for country-specific effects, $\gamma=\alpha \beta$ and $\varepsilon_{i, t}$ is a general error term. In view of the delays likely before plans for FDI can become realised, the desired level of FDI at time $t$ was assumed to be related to the values of time-varying variables at time (t-1) as well as at time $\mathrm{t}^{4}$

Table 1 provides a description of the key possible macroeconomic factors used as the explanatory variables ${ }^{5}$.

\section{Table 1. Variables and Derivations}


FDI inflows to

Thailand

Relative GDP

Annual rate of growth of real GDP per head

Relative wage rates

Bilateral Trade Volume

Exchange rate

Official lending rate Business Infrastructure

Distance

Asia dummy
In real terms (logarithms). Dependent variable.

Ratio of real GDP in Thailand over real GDP in the investing country (all in Thai Bahts). Expected sign positive.

Refers to investing country. (\%) Expected sign uncertain

Ratio of the index of productivity-adjusted real wage rates of the investing country over the corresponding index for Thailand.

Productivity-adjusted real wages were calculated from an index of real wages in local currency divided by an index of real per capita GDP in local currency. For investing countries, this index was then adjusted by the exchange rate index. Expected sign positive.

Real volume of trade of goods (exports plus imports) between the investing country and Thailand (logarithms). Expected sign positive. Index of real exchange rate (Thai Bahts per unit of national currency, adjusted for relative prices). Expected sign positive.

Refers to the investing country. In real terms. Expected sign negative

Refers to investing country. Proxied by the number of top MNCs in investing country in 2003 (as recorded in the World's Giants Global 1000 Interactive Scoreboard from the publication Business Week). (logarithms) Expected sign positive

Geographical distance between the capital of the investing countries and the capital of Thailand. Expected sign negative.

Equals 1 for the Asian countries in the sample (taken as Japan, Singapore, Hong Kong, Taiwan and Korea), 0 otherwise. Expected sign positive.

Our model attempts to include both push factors coming from the investing country, as well pull factors pertaining to Thailand. This distinction is important - push variables will be different at any point in time for all 10 countries, as they relate to the investing country, but pull variables, reflecting the attraction of Thailand compared to all other countries, will be identical. Push/pull variables do not have be included in our model as two separate variables, and theory may help us consider whether a ratio of the two is more appropriate. Thus price variables reflecting relative costs of substitutable investment could more appropriately be included as ratios. ${ }^{6}$ For example, although it is possible to argue that wage rates for both the investing country and in Thailand be considered as separate relevant variables, it seems more likely that changes in the ratio of wage rates between the two countries affect inward FDI to Thailand, assuming labour is perfectly substitutable. Hence the use of a simple ratio such as the index of real wage rates in the UK divided by the index of the real wage rate in Thailand. The greater this ratio, (which will always be positive and greater than zero) the larger one 
might expect FDI from the UK to Thailand to be. Non-linearities in this relationship can be accommodated by the use of logarithms in the dependent variable. Some variables, such as country growth rates, will ideally have separate push and pull components in the model. Thus a change in growth rate in the investing country (reflecting the move towards a recession for example) can be viewed as affecting FDI differently from a change in growth rate in Thailand $^{7}$. Conventional continuous variables such as trade and FDI which could mostly be measured in money terms are transformed by logarithms, whereas ratio and relative variables are not.

Considering the explanatory variables, then their legitimacy for inclusion in the model comes from previous studies, and we summarise as follows. FDI is often motivated by expected sales from the foreign plant or establishment A growing (Thai) economy may provide relatively better opportunities for making profits than other rivals whose economies are growing more slowly (Lim, 1983). For an investing country, a move into recession may provide an impetus for searching abroad, yet on the other hand, a recession may restrict available funds for this purpose. The home and/or foreign-country market size is typically taken into account in empirical FDI studies by using a GDP or GDP growth rate term in the estimating equation (eg. Goh and Wong, 2011). Rugman et al (2006) note that market size is the relative size of each market as a percentage of the total world market, which can be 'population' or GDP per capita. The underlying requirement in the comparative study of investment from 10 countries is to explain why some countries have differing levels of FDI into Thailand. The target market size (pull factor) is the same for all 10 nations at any point in time and changes in this would not explain differences in FDI between countries on its own unless countries have different investment criteria. On the other hand, the economic state of play in the home country (push factor) is a good candidate for explaining differences between investing countries. One possibility is to investigate whether changes in the ratio of market 
size between the two countries (as measured by levels of GDP) might be important. Beyond this, changes in growth rates of GDP/head may have a part to play, from two directions. Firstly, when considering the attractiveness of Thailand compared to their own country, potential investors may pay attention to differences in growth rates - the higher the (expected) growth rate in Thailand, the greater the opportunity for returns from investment, and the higher the likely FDI to Thailand. Secondly, working in the same direction, the higher the growth rate at home, then one could argue that the more likely it is that spare funds will be available for any form of profitable investment abroad. Alternatively, and in contrast, the more likely it is that firms will seek returns in the expanding home market rather than risk looking abroad. These arguments point towards using separate push and pull variables for levels and changes in GDP.

Wage rates could be expected to be an important element of total costs and thus a concern for (profit maximizing) foreign investors when considering production locations. The labour cost differential between investing and host countries has been considered to be essential for domestic investment as it forms the key element of the opportunity cost of foreign investment. Wage rates may reflect labour quality or productivity and this would be positively related to FDI. Agiomirgianakis et al (2006) extend this thinking by including an educational variable to discern labour quality. Their findings indicate that a highly educated and trained labour force is likely to attract labour intensive investment and activate better performance for the foreign firm along with larger productivity. Accordingly, for this study all wages are productivity-adjusted such that it may be posited that the higher the ratio of the index of the investing country's real wage rates to the index of Thailand's wage rates, the higher will be the level of inward FDI to Thailand.

Levels of bilateral trade may provide evidence of the degree of international communication between businesses in the two countries and can lead to spin-offs and 
externalities via the spreading of contacts and useful information about markets and market potential. Most investment projects involved in the trade sector tend to be linked with international trade. The volume of trade can most simply be proxied by summing the level of exports and imports between the two countries. It is expected that the higher the total bilateral trade, the higher will be the inward FDI to Thailand.

Wei and Lui (2001) amongst others assert that any changes in exchange rates affect FDI through relative costs. The depreciation of a host country's currency attracts foreign investors, as labour costs for example will be lower. Hence this study posits that the higher the real exchange rate index (based on units of host country currency which can be exchanged per unit of the investing countries currency, adjusted for relative prices), the higher will be the level of inward FDI to Thailand.

If the cost of borrowing in the investing country is higher than the host country then this may increase the level of FDI within that country, since it becomes cheaper to borrow abroad and build factories there rather than set up in the home country and export. However, there is another side to this argument - if the cost of borrowing in the investing country is lower than the host country then foreign investors may be able to enjoy significant cost advantages over the host country competitors which can be exploited - also leading to increasing FDI. The question is thus related to the source of finance - potential investors from abroad may borrow from the home country or the foreign country. With international capital markets, the situation is even more complex. Further, finance obtained from the host county may not be perfectly substitutable for finance obtained from the investing country. Given that available data for each country only refers to general interest rates and not to any conditions, restrictions and other matters relating to the issue of loans, a more appropriate approach would be to distinguish between the pull and the push effects and separate the interest rates in Thailand as an explanatory variable from the investing country interest rates. 
An upward change in one of these variables would be expected to reduce total FDI, controlling for the other rate of interest.

Irrespective of home market size, countries with many established and larger firms are perhaps more likely to undertake FDI than smaller countries where there are more familyrun, small turnover firms, due to varying expectations, experience, capacity for fact-finding and attitudes to risk, etc. Thus the general business infrastructure of the investing country may be a relevant factor in comparing FDI from different countries. As a non-monetary measure, this should also be less sensitive to random exchange rate collapses and variations, even where exchange rate indices are included in the model (particularly relevant to FarEastern economies during the period considered). Following testing, the preferred model included the numbers of top-ranking MNCs in the investing country. The hypothesis is posited that the higher this number, the higher the level of inward FDI to Thailand from the investing country.

In terms of international trade, distance may proxy transport costs, ceteris paribus, and it may be expected for this reason alone that FDI substitutes for trade as distance increases. On the other hand, it could be used to proxy information costs - as the distance decreases there is potentially greater similarity and insight to a host's country's investment opportunities, customs, legal systems and culture. A number of studies have pointed to geographical distance differences in political institutions, language, religion and social custom which are potential barriers to capital flows. Recognizing that a single variable for distance will not be able to capture all these cultural-type effects, and that there is not a generally accepted alternative, a simple attempt to refine this aspect was made by a dummy variable to contrast any differences likely to arise from working, living and conducting business in Asian countries as opposed to non-Asian countries. ${ }^{8}$ The hypothesis is that FDI to Thailand will be higher from Asian countries than non-Asian. Overall, and forming a more 
general model connected to distance, we adopt a gravity model, positing that the greater the distance between the investing country and Thailand, and the smaller will be the level of inward FDI to Thailand.

\section{Model estimation}

Estimation of the dynamic panel model of equation (3) needs to address problems of the lagged dependent variable, which is correlated with the error term, and of the possibility that the explanatory variables might be endogenous. Both these problems would lead to biased and inconsistent parameter estimates if OLS is used. There is a considerable literature on dynamic panel data models (interested readers are referred to Baltagi (2008)), and the many estimators proposed all attempt in some way to reduce bias or improve efficiency. Most involve differencing and so do not allow for the inclusion of time-invariant variables such as distances. Unfortunately, there is no agreement on the most appropriate method to adopt and our approach is therefore to consider some of the main contenders and compare results. Thus in this paper estimation of equation (3) is undertaken by five panel methods as well as a country-by-country estimation, all of which have advantages and disadvantages. Firstly, a simple OLS permits a base-line comparison, with no account of the panel nature of the data. The many assumptions of this model may be questionable, but this method does permit inclusion of variables such as distance which are fixed over time. To avoid to possible nonstationarity of data (see below), model (2) maintains an OLS estimation, but all variables are in first differences. The lagged dependent variable in equation (3) also leads to 'dynamic panel bias' since shocks to the system feed back to fixed country effects. Panel model (3) removes country effects and estimates the 'within-groups' OLS ${ }^{9}$ and may be an improvement, since although still biased, it becomes consistent as the number of timeobservations ( $\mathrm{T}$ ) becomes large. The fourth refinement in estimation is the move to use instrumental variables. First-difference GMM aims to remove the dynamic panel bias by 
using instrumental variables which are available from the existing data set. By using lags for the dependent variable, as well as for other variables as instruments arranged in a suitable matrix (the lags being less deep for variables not strictly exogenous), a consistent panel estimator is obtained, increasing in efficiency the deeper the lags. Finally the most complex variant (panel model (5)), usually termed system $\mathrm{GMM}^{10}$, estimates a difference equation using lagged levels of variables as instruments at the same time as estimating the levels equation using lagged differences of variables as instruments. This technique produces consistent and more efficient parameter estimates, under certain basic conditions. Further, compared to using differences alone, it allows us to estimate the effects of variables which are time-invariant, such as distances. ${ }^{11}$

As discussed above, the inclusion of separate pull and push variables aimed to consider such matters as whether a change of interest rate in the investing country had the same effect on FDI as an identical change in Thailand. Over the 30 years for which our panel has data, there will have been many shocks which affect FDI from all countries and which will have been accommodated in the error term. The recommendation for GMM panel modelling is to include time dummies to take account of year-by-year differences which affect all countries leading to cross-country error correlation, contradicting one of the assumptions of the model. Unfortunately, such action precludes the use of variables which are the same for each of the 10 investing countries in any year. ${ }^{12}$ Clearly, those characteristics which are just related to Thailand (which include all pull variables such as Baht currency crises, Thai interest rates) cannot be included as separate variables in this panel approach. Effectively, with no variation in pull variables for each investing country, their effects on FDI are subsumed in the time dummies. This is unfortunate but unavoidable. The panel models will only be able to include the variables where the push/pull distinction is blurred or nonexistent. Nevertheless, the approach is still useful in the sense that as all investing countries 
face the same situation in Thailand at any point in time, we might still be able to elicit those factors which push FDI from within the home country to seek new returns abroad. The only alterntaive which is left and which might also enable us to consider the pull factors is a country-by-country analysis. These results will then be compared to the results of a panel analysis. The choice of models is not without trade-off - a country-by-country approach leaves only a few of degrees of freedom given the maximum of 35 observations available for each country, less after lags. In contrast, by merging the data as a panel data, the power to estimate coefficients accurately increases, albeit on the assumption that there is a model common to all investing countries.

To avoid spurious results, the stationarity of all variables was investigated using ADF tests at country level, as well as panel unit root tests. Results were not always consistent, but there is enough evidence to suggest that the dependent variable and the majority of the independent variables are trend stationary, although this may not apply to all countries.

\section{Table 2. FDI in Thailand: Pooled Estimation}

The results of estimating equation (3) by the 5 alternative approaches are presented in Table 2 and show considerable consistency. The coefficient of the lagged dependent variable is approximately 0.5 under most models which suggests a stable adjustment process and under one interpretation suggests that changes to desired levels of FDI occur relatively quickly - one half of any adjustment occurs within one year. Model (2) provides a different picture - the negative coefficient for the lagged dependent variable suggests than an increasing level of FDI in one year is followed by a decrease the next. This is an extreme version of the cycles in FDI observed in Figures 1 and 2. In terms of the stock adjustment model, it means that there is some overcompensation in FDI trajectories - countries do more than adjust to the desired level of FDI in the next year - they exceed it. It is not clear why model (2) is so different in term of this lagged dependent variable - country and time period 
fixed effects have been included. Neither is it out of line with the country-by-country estimations. The alternating signs of lags pertaining to some independent variables suggest difficulty in modelling the large annual swings in FDI, but the overall effect (obtained by summing the 2 coefficients), where significant, is generally of a direction in line with theoretical expectations.

Although there are limitations when there are a large number of instruments, a Sargan test indicated that the additional restrictions implied by System-GMM were not valid. On the other hand, Sargan tests on excluding instruments from the GMM-Difference model suggested that the restrictions imposed by the set of level instruments as used in Model 4 were generally acceptable. Doornik et al (2006) recommend comparing the GMM and Within-Groups estimates, due to the latter's consistency as the number of time-periods increases. In our case, comparing models (3) and (4) shows considerable similarity, both in terms of coefficient estimates and in the standard errors. On the whole, and looking at all the model estimates, however, one can have some confidence that biases of the different estimators are not major and that it is in the precision where differences are more notable. Overall, and on grounds of efficiency, it would seem that models (3) and (4) are useful and although each may be affected in differing degrees by bias, endogeneity and inconsistency, we henceforth confine our attention to these, but using models (1) and (5) for consideration of the time-invariant variables.

Considering first these time-invariant variables, then as expected the greater the distance between the investing countries and Thailand, the smaller will be inward FDI to Thailand, consistent with other studies such as Guerin (2006). The Asian dummy variable, however, has an unexpected sign, although it is not significant in the system-GMM estimation. If there is a counter-intuitive finding to be explained, then one might suggest that Asian countries or those with similar cultural backgrounds to Thailand in the sample are 
exhausting the benefits from FDI amongst themselves and are seeking out new markets where returns are higher than in Thailand. Other studies such as Wei and Lui (2001) also identify a negative significant relationship between cultural difference and FDI. There is less evidence (only from the OLS model) that the number of top multinationals in the investing country has a positive impact on FDI - most likely the medium and relatively smaller companies are equally keen on finding good new investment opportunities abroad as those who have already completed large tranches of FDI.

Turning to coefficients estimated in all models, there is reasonably consistent evidence to suggest that the higher the growth in GDP per head in the home country, then the higher will be the FDI in Thailand from that country. This is quite consistent with the idea that in times of prosperity, then firms look abroad for potential returns, as well as at home. Money earned as profits can be used to further longer-term returns from FDI, as well as at home and/or being distributed to shareholders. Economies in recession with slow growth have less inclination or resources to expand abroad. Models (3), (4) and (5) were all in agreement that every 1 percentage point increase in growth per head in the investing country would lead to a $0.1 \%$ increase in desired FDI to Thailand. There was also an indication in models (3) and (4) that firms assessed the relative size of markets (as measured by GDP) between the home country and Thailand. This would not be unexpected, and the more that the market size in Thailand was increasing compared to the domestic market, the more likely firms are to consider FDI in Thailand. The importance of market size and growth has been found in many other studies (eg Agiomirgianakis et al (2006). If Thailand seeks to continue to increase FDI, then this is quite consistent with its policy on growth. In addition, in seeking out any countries with which to cultivate relations, it would be best to concentrate on those expecting high growth rates in the near future. 
The effect of relative real wage rates on FDI was significant in all models. A relatively cheaper labour force in Thailand increases the level of FDI, presumably as opposed to the use of production at home followed by trade. The effect of a 1 point rise in the index of real wages in the investing country compared to Thailand might be expected to lead to between 3.2\% (within groups) and 3.8\% (System GMM) increase in desired FDI. Model (4) was in-between. Not all empirical work has supported this relationship in all countries, (eg Meyer (1995) suggests that FDI in Central and Eastern Europe is not primarily motivated by low labour costs), although not all studies controlled for productivity. Frobel et al (1980), from a survey of companies in Germany, found that where the developing countries had explicit investment attraction policies such as export processing zones where the virtue of lower labour costs was signaled, this was exploited. This would suggest that even if Thailand can maintain relatively lower wage rates, their impact on FDI can be improved by ensuring that this information and its implications for costs are clearly relayed to prospective investors.

The coefficient on the total level of bilateral trade has the expected positive sign across all models and is also significant in these models - countries which already "do business" with Thailand are the ones more likely to undertake FDI, and this propensity increases with the volume of trade. The estimates suggest that elasticity of desired FDI (see equation (2)) as a result of changes in trade is between 1.3 (Difference GMM) and 1.9 (System GMM). Although increasing trade by itself may not on its own directly increase FDI, it is likely that fostering links between countries by a range of methods does lead to increased trade and by a similar mechanism to increased FDI, although one might expect some lag between the two. This was also confirmed by Wei and Lui (2001) amongst others.

Relative real exchange rates were not identified as a significant determinant of FDI (except in model (2)). This is contrary to many previous studies (eg. Barrell and Pain, 1998) and an explanation is likely to lie in the dynamics of FDI, which will would involve a 
consideration of stickiness, expectations, disequilibrium and the timing of investments (e.g. see Kogut and Chang, 1996) and, especially where it involves building on green-field sites, is likely to be based on long-term returns. Changes in real exchange rates may however be perceived as short-term and hence discounted, or firms may expect depreciation in the real exchange rate to be shortly followed by a reversal to a long-run stable level.

The real interest rate in the investing country is shown as having no effect on FDI into Thailand, a result which was not expected. There may be some international differences in attitudes to risk-taking and borrowing here since for example Barrell and Pain (1999) found that the low cost of funding certainly influenced Japanese investment during the 1980s. Belderbos and Sleuwegen (1996) however found that lending cost effects influenced the investment decisions of Japanese electronic firms in Western countries but not in the context of Asia. We must conclude that the 'pushing' potential of cases where cheaper finance is available at home is too small an aspect of the decision to undertake FDI to be picked up at aggregate level. Correspondingly, to the extent that sources of funds are substitutable, although this cannot be shown from this model, one would expect there to be a comparable (and non-existent) effect on FDI of changes in real interest rates in Thailand.

As indicated above, in order to assess the importance of any pull factors attracting FDI to Thailand, a non-pooled estimation technique is required, so permitting the inclusion of variables which related only to Thailand (such as the growth in Thai GDP per head) and which were identical at any point in time for all potential investors. Thus estimation of desired FDI to Thailand from each of the 10 countries was undertaken separately. ${ }^{13}$ Due to the likely non-stationarity in levels of many variables, the models were estimated in first differences. ${ }^{14}$

As might be expected from Figures 1 and 2, the erratic nature of FDI from each country was revealed in low adjusted R-squared values in each of the 10 models. Indeed, 
there could be an argument made that FDI was little more than a random walk with drift or a trend-stationary process. The only exceptions might be Australia, Canada and Taiwan, but without further explanations, even this could be a spurious finding, with problems of autocorrelation revealed. The strong link between the total volume of trade and FDI which was shown in the pooled model only continues in a very limited manner at the country level analysis. It is difficult to know whether these results reflect the lower power of the countryby-country approach to detect relationships, but it is evident that we are unable to isolate any general pull factors related to Thailand that apply equally well in attracting FDI from every one of the sample of 10 countries.

It is possible is that the relevant factors which attract FDI to Thailand from other countries differ in both relevance and strength according to country, rendering a pooled model, despite their being more robust and yielding consistent estimators, inappropriate. Yet many empirical models do assume that the effects of each variable on FDI are identical for each country, with no a priori reason for this to be the case. Differences between the motives, aspirations, risk-averseness and principles of investment across the range of countries considered may mean that a variable is considered more important in determining FDI to Thailand from one country than from another. This is a criticism which can be made at our own model, but the difficulty has at least been recognised. Yet other researchers estimate global models where the determinants of FDI are estimated using pair-wise data. This is an even more extreme assumption effectively imposing restrictions on coefficients between all countries and these results should be treated with caution.

\section{Concluding remarks and policy implications}

A partial adjustment model of the determinants of FDI in Thailand is estimated using a dynamic pooled time series approach and employing a specially created and original dataset 
covering annual data over the period 1970-2004, employing data from 10 countries. Careful consideration was given to the manner in which all variables might affect FDI to Thailand, in particular the distinction between push and pull factors, and attention was paid to problems of stationarity and estimation technique.

In terms of policy, not all determinants of inward FDI are under the direct control of the host country and it may be difficult if not impossible for the host country to change these variables. This would include geographical distances, even if this is a proxy for legal and other cultural differences. Push factors such as changes in GDP of the investing country, and relative market sizes to a certain extent, are also important in influencing FDI, as a growing GDP at home allows access to more financial resources to expand abroad as well. A key determinant of FDI is the total bi-lateral trade between a country and Thailand, suggesting that fostering good relations and cooperative arrangements which lead to improved collaboration on trade matters in general may be at least as effective in attracting FDI as monetary instruments. Some determinants it may be inadvisable to influence - despite relative wage rates being important, this does not imply a policy of low wages should be pursued, as this is likely to be counter to government policy of increasing standards of living over time. In any case, there is the possibility that FDI may directly increase the wages of local workers (Tomohara and Takii, 2011). To hone investigation of the pull factors, the analysis was repeated on a country-by-country basis. This reduced the sample size significantly and the evidence suggested that at this level of detail, very few variables were able to consistently explain changes in FDI for any country. Thus macroeconomic policy to attract FDI to Thailand via any manipulation of real exchange rates or efforts to increase GDP is likely to be less effective than expected. Although Thai policy since 1959 has implied that FDI is an instrument to increase economic growth, it is equally evident that economic growth may be an instrument to change FDI. Indeed Mah found only the latter direction of 
causality in his study of China (2010). Complex relationships are involved internally, and their understanding is vital to ensure consistent government policy.

Given the extent of the swings in FDI observed from each of the 10 countries over the 34 year-period of this study, it is not so surprising that explanations have been hard to find from macroeconomic variables. The implications for Thailand are clear - the scope for attracting more FDI from these 10 countries using the specific major instruments of macro-economic policy is limited. If macroeconomic relationships exist, these may be different from country to country, and government policy should take account of this, a conclusion also reached by Abdelhafidh (2013). If at country level it is not the macro variables which are key to bringing in FDI, then concentrating on the direct policies to bring in FDI (tax incentives, etc) may be the more effective way to increase FDI. This is supported in other work, such as Alguacil et al. (2011) who found that the institutional environment and local conditions played a key role in growth determination. Investment decisions will frequently be based on long-term expectations and personal contacts, information about which is not contained in macroeconomic variables. The use of political visitations, trade delegations etc. both from and in the investing countries, which are likely to be asynchronous in terms of when they take place will also affect FDI and may explain the large fluctuations. Thus developing nations who wish to increase incoming FDI can assist matters more by fostering good relationships in general than concentrating on attaining specific macroeconomic conditions. To attract FDI, it is this more down-to-earth area of policy on which governments should concentrate, as opposed to the traditional macro-economic variables. Hence although in Thailand the Ministries of Industry and Finance share the same aims, both being party to implementing the National Plans, it would seem that the more local and specific initiatives under the control of the Ministry of Industry are those which are most likely to influence FDI.

\section{Acknowledgments}


The authors are grateful for financial support from the Royal Thai Government (Ministry of Education) and for data access to the Bank of Thailand. Thanks are also given to several anonymous referees.

\section{References}

Abdelhafidh, S., (2013). Potential financing sources of investment and economic growth in North African countries: A causality analysis, Journal of Policy Modeling, 35, 150-169.

Agiomirgianakis, G., Asterious, D. and Papathoma, K. (2006). The Determinants of Foreign Direct Iinvestment: a Panel Data Study for the OECD Countries. (Working Paper No. 03/06).London: Department of Economics, School of Social Sciences, City University.

Alguacil, M., Cuadros, A. and Orts, V. (2011). Inward FDI and growth; The role of macroeconomic and institutional environment, Journal of Policy Modeling, 33, 481-496.

Baltagi, B (2008) Econometric Analysis of Panel Data. Fourth Edition.New York: Wiley.

Barrell, R. and Pain, N. (1998). Real exchange rates, agglomerations and irreversibilities: macroeconomic policy and FDI in EMU, Oxford Review of Economic Policy, 14 (3), 152-167.

(1999).Trade Restraints and Japanese Direct Investment Flows. European Economic Review, 43(1),

$29-45$.

Belderbos, R. and Sleuwaegen, L. (1996). Japanese Firms and the Decision to Invest Abroad: Business Groups and Regional Core Networks. The Review of Economics and Statistics, 78(2), 214-220.

Doornik, J., Arellano, M. and Bond, S. (2006) Panel Data estimation using DPD for Ox, available at http://www.doornik.com/download.html

Faeth, I. (2009), Determinants of Foreign Direct Investment - A Tale of Nine Theoretical Models, Journal of Economic Surveys, 23 (1), 165-196.

Frobel, F., Heinrichs, J. and Kreye, O. (1980). The New International Division of Labour, Cambridge, UK: Cambridge University Press.

Goh, S. and Wong, K., (2011). Malaysia's outward FDI: The effects of market size and government policy, Journal of Policy Modeling, 33, 497-510.

Guerin, S.S. (2006). The Role of Geography in Financial and Economic Integration: A Comparative Analysis of Foreign Direct Investment, Trade and Portfolio Investment Flows. The World Economy, 29 (2), 189-210.

Hofstede, G. (2001). Culture's Consequences: Comparing Values, Behaviours, Institutions, and Organization Across Nations (2nd ed.). Thousand Oaks, California. London: Sage Publications.

International Monetary Fund. (1993). Balance of Payments Manual, fifth edition. Washington, DC. IMF. Retrieved February 28, 2008, from the IMF website: http://www.imf.org/external/np/sta/bop/BOPman.pdf Kogut, B. and Chang, S.J. (1996). Platform Investments and Volatile Exchange Rates: Direct Investment in the U.S. by Japanese Electronic Companies. The Review of Economics and Statistics,78(2), 221-231.

Lim, D. (1983). Fiscal Incentives and Direct Foreign Investment in Less Developed Countries, Journal of Development Studies, 19, 207-212.

Mah, J., (2010), Foreign direct investment inflows and economic growth of China, Journal of Policy Modeling, 32, 155158.

Merlevede, B. and Schoors, K, (2009). Privatisation and foreign direct investment in 10 transition countries. PostCommunist Economies, 21(2), 143-156.

Meyer, K.E., (1995). Direct Foreign Investment in Eastern Europe: The Role of Labour Costs, Comparative Economics Studies, 37(4), 69-88.

Pupphavesa, W. and Pussarungsri, B. (1994). FDI in Thailand. Bangkok: Thailand Development Research Institute. Rugman, A.M., \& Collinson, S. and Hodgetts, R.M. (2006). International Business (4th ed.). Harlow: Financial Times Prentice Hall.

Tomohara, A. and Takii, S., (2011). Does Globalization Benefit Developing Countries? Effects of FDI on Local Wages, Journal of Policy Modeling, 33, 511-521.

Wattanadumrong, B., Collins, A. and Snell, M, (2010). Still Big in Bangkok? An Empirical Analysis of the Regional Distribution of Foreign Direct Investment in Thailand, International Journal of the Economics of Business, 17 (3), 329348.

Wei, Y. and Liu, X. (2001). Foreign Direct Investment in China: Determinants and Impact. Cheltenham: Edward Elgar. Yeyati, E. V., Panizza, U. and Stein, E. (2007). The Cyclical Nature of North-South FDI Flows, Journal of International Money and Finance, 26, 104-130.

Notes

1 Data were acquired from Band of Thailand statistics, and are collected under a Balance of Payments (BOP) framework closely corresponding to the BPM5 recommendations of the International Monetary Fund (IMF 1993) standard. FDI components include equity capital (where a direct investor owns 10\% or more of the ordinary shares), reinvested earnings and other capital (mainly intra-industry loans). There are limitations in data collection in these components for some countries and reported data on FDI is not fully comparable across all countries, especially with regard to reinvested earnings because the data which depends on company surveys is unreported in 
Taking the Thai Trail

many countries. Our data analysis stops at 2004 due to the political events in Thailand after this time which are likely to have led to more unstable and unpredictable FDI.

2 Over the data period, these countries typically formed over $80 \%$ of Thailand's FDI. There was some exception to this in the period $1993-$ 1996, when this fell to a low varying between 60\%-75\% due to an unusually high level of FDI from outside Thailand's usual trading partners.

3Faeth (2009) provides a recent overview. In modeling FDI, it should be noted that changes in a portion of the equity and loans held by a multinational affiliate can be viewed differently to changes in more standard measures of investment such as fixed investment. This is because although FDI is often used to finance increases in fixed asset stocks (fixed investment) it may also be used to reduce dependence on local equity and/or loans. Many MNCs also use their FDI funds for purchases of non-fixed assets such as land and financial assets. Clearly some of these purchases may well be speculative in purpose and imply a balance sheet restructuring motive for FDI. This applies equally to producers of goods and services, as well as to banks, excluded from this analysis. This paper confines itself to macro-level data and as such is not able to analyse either this motive or trends in particular sectors, for which more detailed micro data such as firm-level questionnaires would be required. Neither was data available on a consistent basis on variables which could act as proxies for speculative and balance-sheet restructuring motives for FDI - for example, data on land prices and/or indices of shares in property companies.

4 More complicated lag structures were investigated but at the expense of parsimony and did little to aid understanding.

5 All variables except the number of top companies and geographical distance have been adjusted by a GDP deflator Data sources available from the authors.

6 A range of ratios can usually be obtained from two absolute figures (by comparing the one for the investing country with the one for Thailand), any of which could be argued as suitable determinants of FDI to Thailand.

7

In any case, using a ratio would be incorrect for variables measured as percentages if either both of the growth rates are negative (e.g. when a Thai growth rate was $-6 \%$ and the UK $+4 \%$ the resultant variable would be indistinguishable from the situation when the Thai growth rate was $+6 \%$ and the UK $-4 \%$ ). A simple difference in the percentages (using the excess of the growth rate in UK over growth rate in the Thailand) is one of several alternatives for constructing a suitable variable.

8 A cultural difference variable based on Hofstede (2001) was also used but had similar impact

9 Estimated coefficients are identical to including dummies for each country - the 'least squares dummy variables' estimator.

10 The GMM approach has now been widely discussed in the literature and incorporated into standard econometric software. We do not explain the technique in full here and interested readers are referred to Baltagi (2008).

11 Further discussion relating to the statistical and econometric properties of these estimators and choice of instruments may be found in a longer version of this paper, at http://snellm.myweb.port.ac.uk/papers/JPMlongversionwithfigs.docx

12 Indeed, experimentation with the removal of time dummies made the model results particularly sensitive to the specification of lag lengths, etc.

13 This approach also permitted the addition of further variables, such as a trade-weighted index of the Thai Baht (to proxy Thai currencycrises), and the number of tourism arrivals in Thailand (to proxy political stability in Thailand). These proved insignificant.

14 Given the small number of degrees of freedom, it was necessary to reduce the number of variables, (using significance levels as criteria).

The full set of results is in the longer version of this paper at http://snellm.myweb.port.ac.uk/papers/JPMlongversionwithfigs.docx 
Taking the Thai Trail

Figure 1. Total Real FDI - Thailand 1970 - 2004

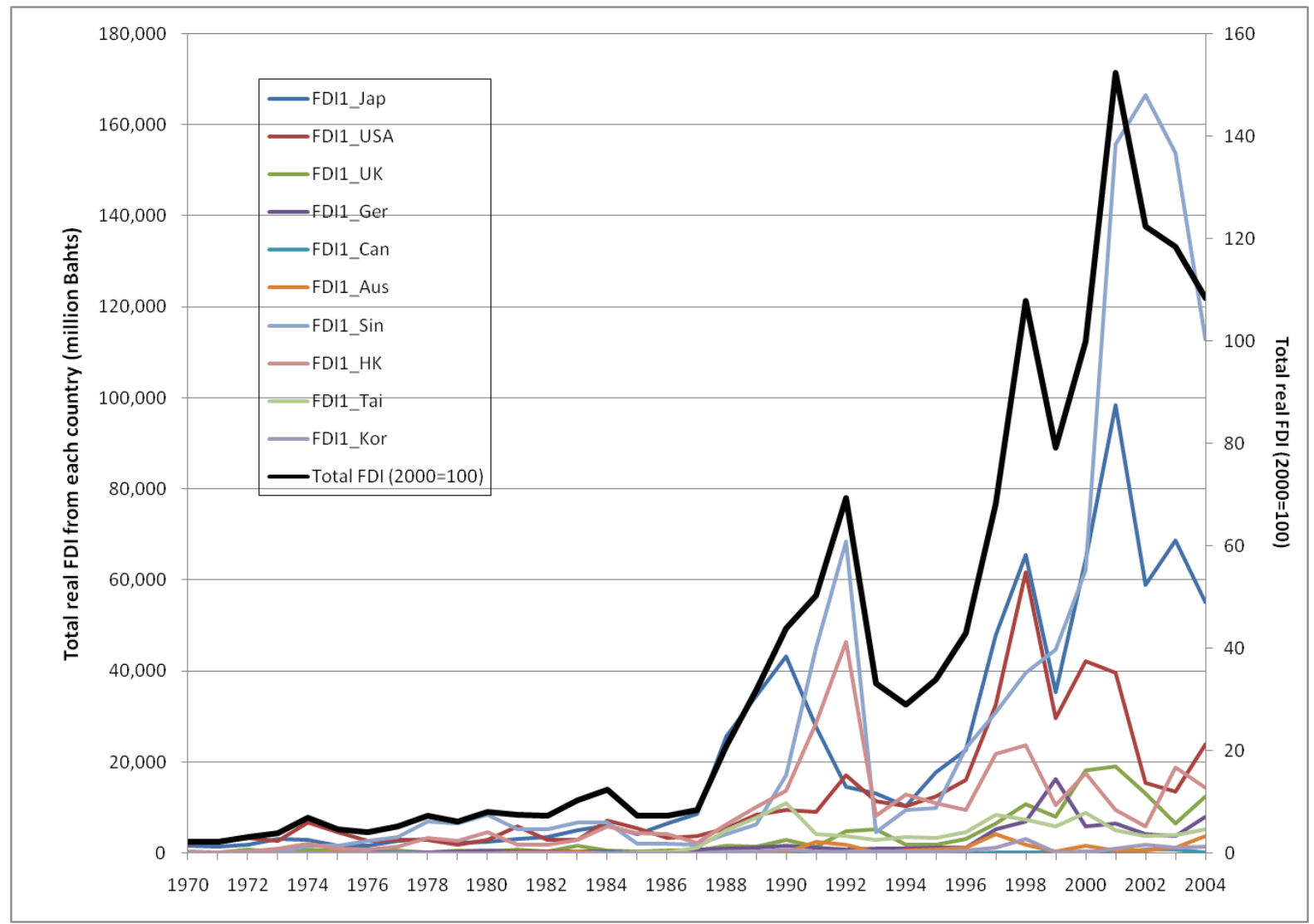

Figure 2. Relative Shares in Real FDI - Thailand 1970 - 2004

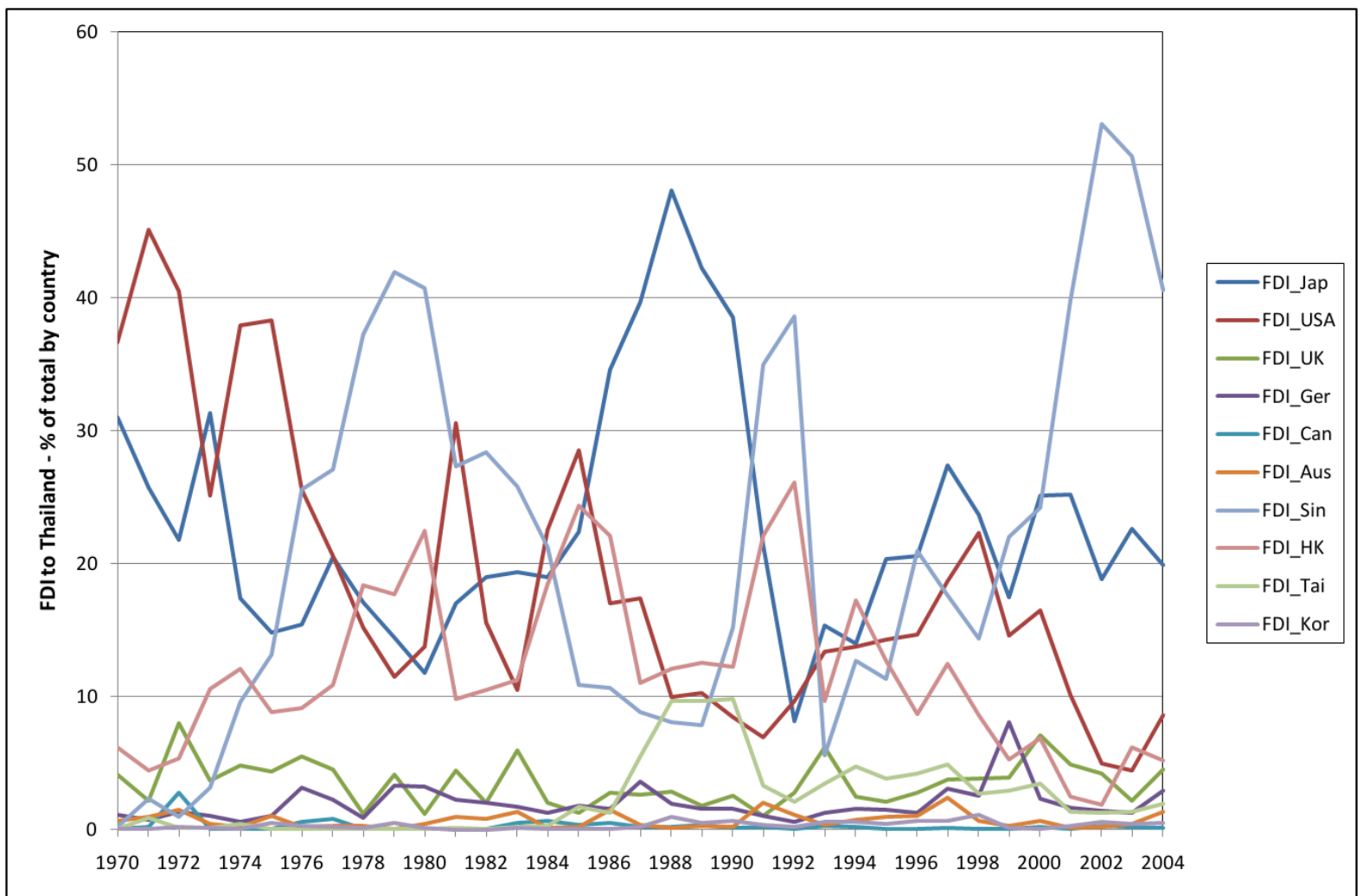

PAGE 25 
Taking the Thai Trail

\begin{tabular}{|c|c|c|c|c|c|c|c|c|c|c|c|}
\hline & & \multicolumn{3}{|c|}{ Method of Estimation } & & \multirow[b]{2}{*}{ (3) } & & \multirow[b]{2}{*}{ (4) } & & \multirow[b]{2}{*}{ (5) } & \\
\hline & & (1) & & (2) & & & & & & & \\
\hline \multirow[t]{2}{*}{ Independent Variables } & LAG & \multicolumn{2}{|c|}{ OLS in Levels } & \multicolumn{2}{|c|}{ OLS in differences } & \multicolumn{2}{|c|}{ Within-Groups OLS } & \multicolumn{2}{|c|}{ First-Difference GMM } & \multicolumn{2}{|c|}{ System GMM } \\
\hline & & Coeff. & t-prob & Coeff. & t-prob & Coeff. & t-prob & Coeff. & t-prob & Coeff. & t-prob \\
\hline Constant & & 11.2879 & $0.000 * * *$ & 0.4226 & 0.325 & & & 0.5915 & 0.449 & 4.6897 & 0.467 \\
\hline Foreign Direct Investment (log) & 1 & 0.5603 & $0.000 * * *$ & -0.2796 & $0.000 * * *$ & 0.4979 & $0.000 * * *$ & 0.4952 & $0.000 * * *$ & 0.4577 & $0.000 * * *$ \\
\hline \multirow[t]{2}{*}{ Relative GDP } & 0 & -0.1534 & 0.669 & -0.222 & 0.338 & 0.3278 & $0.069 *$ & 0.3038 & $0.1^{*}$ & 0.5882 & 0.155 \\
\hline & 1 & 0.0894 & 0.82 & -0.8378 & $0.034 * *$ & -0.0874 & 0.674 & -0.0163 & 0.948 & -0.1686 & 0.519 \\
\hline \multirow[t]{2}{*}{ GDP/Head growth - investing cty. } & 0 & -0.0112 & 0.691 & -0.0522 & 0.188 & -0.0047 & 0.853 & -0.0054 & 0.839 & -0.0091 & 0.76 \\
\hline & 1 & 0.0439 & 0.111 & -0.0122 & 0.589 & 0.0529 & $0.046^{* *}$ & 0.0528 & $0.052^{*}$ & 0.0583 & $0.081^{*}$ \\
\hline \multirow[t]{2}{*}{ Relative Real Wage } & 0 & 1.9212 & $0.015^{* *}$ & 0.7464 & 0.2 & 1.9288 & $0.009 * * *$ & 2.1087 & $0.001 * * *$ & 2.3917 & $0.001^{* * *}$ \\
\hline & 1 & -1.3669 & $0.099^{*}$ & 3.2027 & $0.009 * * *$ & -0.3389 & 0.677 & -0.4216 & 0.663 & -0.3115 & 0.799 \\
\hline \multirow[t]{2}{*}{ Real Volume of Trade (log) } & 0 & 1.2401 & $0.011^{* *}$ & 1.4209 & $0.049 * *$ & 1.269 & $0.027^{* *}$ & 1.3079 & $0.015^{* *}$ & 1.9482 & $0.007^{* * *}$ \\
\hline & 1 & -0.794 & $0.067^{*}$ & 0.6663 & 0.477 & -0.6926 & $0.049 * *$ & -0.6644 & $0.046^{* *}$ & -0.9403 & $0.036^{* *}$ \\
\hline \multirow[t]{2}{*}{ Real Exchange Rate Index } & 0 & -0.6475 & 0.545 & 0.6359 & 0.441 & 0.1263 & 0.905 & 0.0383 & 0.97 & 0.1634 & 0.895 \\
\hline & 1 & 0.5342 & 0.549 & -2.5771 & $0.017^{* *}$ & 0.2588 & 0.745 & 0.2959 & 0.711 & 0.0569 & 0.959 \\
\hline \multirow[t]{2}{*}{ Interest Rate - investing cty. } & 0 & 0.0111 & 0.584 & 0.0221 & 0.209 & 0.0196 & 0.331 & 0.0121 & 0.563 & 0.0081 & 0.753 \\
\hline & 1 & -0.0091 & 0.63 & -0.01222 & 0.437 & -0.0078 & 0.677 & -0.0049 & 0.813 & -0.0072 & 0.771 \\
\hline No.of Top Multinationals (log) & & 0.5932 & $0.000 * * *$ & & & & & & & 0.7753 & 0.137 \\
\hline Total Distance (log) & & -1.8115 & $0.000 * * *$ & & & & & & & -1.8374 & $0.01 * * *$ \\
\hline Asia dummy & & -1.5452 & $0.000 * * *$ & & & & & & & -1.8218 & 0.137 \\
\hline No. Of Observations & & 340 & & 330 & & 340 & & 330 & & 340 & \\
\hline R-squared & & 0.865 & & 0.291 & & & & & & & \\
\hline Time Dummies & & 33 & & 32 & & 33 & & 32 & & 33 & \\
\hline Sargan Test [df] & & & & & & & & \multicolumn{2}{|c|}{$276.1(p=1.000)[443]$} & \multicolumn{2}{|c|}{$460.2(p=0.655)[473]$} \\
\hline AR(1) Test & & \multicolumn{2}{|c|}{$-2.241(p=0.025)^{* *}$} & \multicolumn{2}{|c|}{$-1.097(p=0.272)$} & \multicolumn{2}{|c|}{$-2.108(p=0.035)^{* *}$} & \multirow{2}{*}{\multicolumn{2}{|c|}{$\begin{array}{l}-2.096(p=0.036)^{* *} \\
-1.177(p=0.239)\end{array}$}} & \multirow{2}{*}{\multicolumn{2}{|c|}{$\begin{array}{l}-2.133(p=0.033)^{* *} \\
-1.176(p=0.240)\end{array}$}} \\
\hline AR(2) Test & & & & & & & & & & & \\
\hline \multirow[t]{10}{*}{ Notes: } & 1. Depende & Variable is I & g FDI; Coeff. & efficient & & & & & & & \\
\hline & 2. Models ( & 4) and (5) a & e all estimat & first diffe & ences & & & & & & \\
\hline & 3. $* * *, * *$ & present $1 \%$ & $5 \%$ and $10 \%$ & ificance le & els respecti & & & & & & \\
\hline & 4. All variak & measured & t 2000 const & orices & & & & & & & \\
\hline & 5. Robust s & dard errors & used & & & & & & & & \\
\hline & 6. Time Dur & ies includec & in estimatior & not incluc & ed here for & ity. Mode & so includes g & up dumm & & & \\
\hline & 7. GMM Le & instrument & in model (4) & Dummies, & FDI (lags 2-1 & EXNDX (la & ), IR (lags 2-3 & iDPHGR ( & gs 2-3) & & \\
\hline & 8. GMM Ins & ments in $\mathrm{m}$ & del (5) are th & in (4) plus, & for level equ & ns: FDI (d & ice lagged 1) & & & & \\
\hline & 9. GMM Mc & Is are one-s & & & & & & & & & \\
\hline & 10. Estimat & using DPD $f$ & r OX (http:// & v.doornik. & om/downlo & html) & & & & & \\
\hline
\end{tabular}

